\title{
1987 Election Results: Baglin, Chang, Kelso, and Phillips
}

John Baglin, Bob Chang, Susan Kelso, and Julia Phillips have been selected by the membership of MRS to fill four top offices of the Society in 1987. Along with 1987 President Kathy Taylor, John Baglin will serve as First Vice President and PresidentElect, and Bob Chang will serve as Second Vice President. They will begin their oneyear terms of office January 1, 1987. Treasurer Susan Kelso and Secretary Julia Phillips will also begin their terms of office on January 1, 1987 and serve for two consecutive years.

"These four new members of the Executive Committee bring with them an extensive record of contributions to the $\mathrm{Ma}$ terials Research Society and their respective professions. Together with 1987 President Kathy Taylor, they form a strong team which will further the interests of the Society in many ways in the coming months," remarked 1986 President Gordon Pike.

Six candidates were also elected to Council, MRS's policymaking body. The newly elected Councillors are David K. Biegelsen, Rodney C. Ewing, Robert A. Huggins, Herbert H. Johnson, John M. Poate, and C.W. (Woody) White. The Councillors will serve three-year terms, also beginning January 1, 1987

\section{John E.E. Baglin}

First Vice President and President-Elect

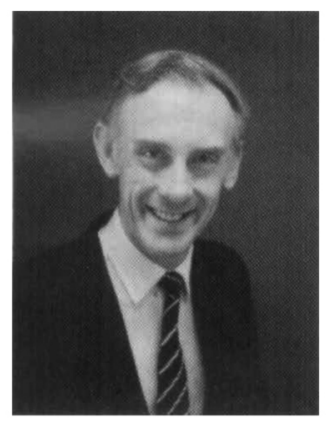

"MRS is enjoying dynamic growth, and we who are members of MRS now have the excitement, the challenge, and the responsibility of shaping this growth. . We must strengthen and enrich MRS's basic activities, while preserving the spirit of enterprise and innovation that has been the special mark of MRS since its founding."

John Baglin has been with IBM T.J. Watson Research Center since 1978 and was previously assistant professor of physics at lowa State University. His research interests include physics of thin film structures, interfaces, and interactions; radiation effects in solids; ion beam and laser modification of materials; and ion beam analysis. He also has a strong interest in the teaching of science. He is a member of the American Physical Society, Sigma Xi, and councillor of the Böhmische Physical Society.

Baglin has been a member of MRS since 1978 , serving in a number of capacities. He chaired the 1983 symposium on Thin Films and Interfaces, and served as editor of the resulting proceedings volume. He was chair of the 1984 Publications Committee and of the 1985 Subcommittee on Book Publishing. During those years, he worked to establish the in-house proceedings publishing operation of MRS headquarters, which has resulted in timely and costeffective publication of about 30 titles to date. He was also actively involved in planning for the new Journal of Materials Research. Baglin is a member of the Program Committee, and served as a general program chairman for the 1985 Fall Meeting. Elected Second Vice President for 1986, Baglin is currently responsible for overseeing the committees on Education, Publications, and Public Relations.

\section{R.P.H. Chang}

Second Vice President

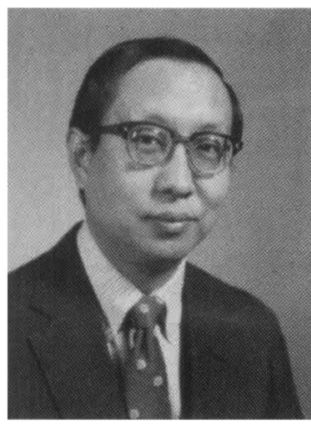

"MRS is proud of its symposium organizers who work extremely hard to put forward the best and well balanced interdisciplinary meetings each year. As a result, our society has been experiencing a period of dynamic growth and excitement."

Bob Chang joined the research division of AT\& T Bell Laboratories in 1971 to start research in experimental plasma physics, concentrating on nonlinear plasma wave phenomena. Since 1976, his research interests have been the study of plasma-solid surface interactions and thin films for electronics. He is currently working on electronic materials for integrated optoelectronic devices. Chang has over 170 publications (including patents) to his credit. As of this summer, Chang accepted an appointment as a professor in the Department of Materials Science and Engineering at Northwestern University, while also serving as a consultant to AT\&T Bell Laboratories.

Chang has been a very active member of MRS in various capacities. In 1984, he organized the first symposium on Plasma Synthesis and Etching of Electronic Materials, and obtained 16 corporate sponsors to support that symposium. He is one of the meeting chairs for the 1986 MRS Fall Meeting. Since 1985, he has been Chairman, International Relations, with the responsibility of encouraging MRS-style activities around the world. He is working with scientists in Asia to plan an MRS-style international meeting for 1988 in Japan with MRS as one of the sponsors. Chang is an active member of the Program, Awards, Long-Range Planning, and Corporate Participation Committees. He is also a Councillor

\section{Susan M. Kelso}

Treasurer

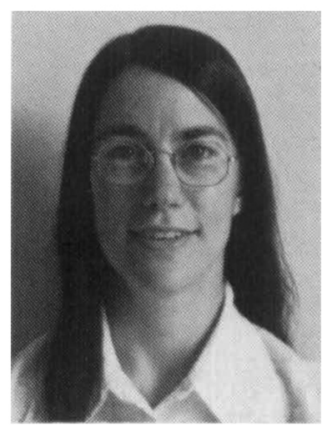

"Because of the rapid growth of MRS, in both members and services, the budgeting process has a worrisome uncertainty in it. The Treasurer must recognize the areas of weakness and carefully monitor the income and expenditures of the Society. The Treasurer also needs to have a long-term financial plan.

Sue Kelso has been a member of the research staff at Xerox Palo Alto Research Center since 1981. Her research interests include spectroscopic ellipsometry for in situ investigations of thin films and interfaces, and modulation, luminescence, and synchrotron radiation reflectance spectroscopies for studies of electronic materials. She is a member of MRS, APS, AAPT, the Association of Women in Science, Sigma $X_{i}$, and Phi Beta Kappa. Kelso has been active in MRS since joining in 1983. She was meeting co-chair for the second MRS Spring Meeting in San Francisco in 1985. She is currently chair of the Finance Committee and a member of the Program Committee and the Awards Committee.

\section{Julia M. Phillips}

Secretary

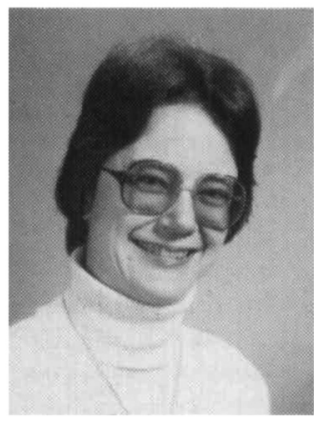

"In the face of great expansion of both its membership and meeting size, [MRS] must endeavor to retain its flexibility and close touch with the grass-roots materials research community. The MRS leadership must strive to retain the attributes of the Society which led to its rapid rise, or risk its becoming just another large professional organization."

Julia Phillips has been a member of the technical staff in the Interface Physics

Continued 
Research Department of AT\&T Bell Laboratories since 1981. Her research interests include grow th by molecular beam epitaxy of insulators and metals on semiconductors, and structural and electrical characterization of these heterostructures; ion beam analysis; and application of rapid thermal processing techniques to heteroepitaxy. Phillips is a member of the American Physical Society, Sigma $X_{i}$, and the Electronic Materials Committee of The Metallurgical Society. She has served MRS as chair of the Publicity and Public Relations Committee (1984-1985), chair of the Corporate Participation Committee (1986), and is a symposium organizer for the 1987 Spring Meeting symposium on Heteroepitaxy on Silicon Technology.

\section{Councillors}

\section{David K. Biegelsen \\ Councillor}

David Biegelsen is a principal scientist at the Xerox Palo Alto Research Center. His most recent research involves the fundamental aspects of heteroepitaxy. Biegelsen's areas of expertise include quasiparticle interactions in superfluids, acousto-optic interactions, spin resonance in a morphous semiconductors and related systems, and laser-induced thin film silicon crystallization. He has been the author of numerous papers, book chapters, and patents, and has edited three books in the above areas. Biegelsen has been actively involved in MRS in many capacities. He was a co-chair of the 1984 symposium on Energy Beam Solid Interactions, a meeting co-chair of the 1985 Fall Meeting, and member of the Program Committee and the Long-Range Planning Committee.

\section{Rodney C. Ewing \\ Councillor}

Rod Ewing is professor of geology at the University of New Mexico. A member of numerous professional societies, he has been a guest or visiting scientist at several national laboratories and the Hahn-MeitnerInstitut in Berlin. His research interests include radiation effects in crystalline materials, the mineralogy and crystal chemistry of complex $\mathrm{Nb}-\mathrm{Ta}-\mathrm{Ti}$ oxides, the application of natural analogues to the evaluation of the long-term stability of radioactive waste forms, low-temperature corrosion of silicate glasses, and the application of synchrotron radiation to the study of radiation-damaged materials. Ewing has served as Councillor and Secretary for MRS. He has also been a member of the Program Committee and an associate editor for the proceedings volumes from two MRS symposia on the Scientific Basis for Nuclear Waste Management. He has chaired the Education and the Membership Committees and has been a member of the Nominating and the Long-Range Planning Committees.

\section{Robert A. Huggins}

\section{Councillor}

Robert Huggins joined the Stanford University faculty in 1954. He was Director of Stanford's Center for Materials Research from its initiation in 1961 until 1977. The recipient of numerous awards, his research activities have included studies of imperfections in crystals, solid-state kinetics, magnetism, mechanical behavior of solids, catalysis, crystal growth, and solid state electrochemistry. He has recently focused on defects in solids and solid-state ionic phenomena involving solid electrolytes and mixed ionic-electronic conducting materials containing atomic or ionic species with unusally high mobility, as well as their use in novel battery systems, hydrogen storage, electrochromic display devices, sensors, and in enhanced heterogeneous catalysis.

A much published author, he is also editor of the series Annual Review of Materials Science, editor of Solid State Ionics, associate editor of Materials Resenrch Bulletin, and serves on several editorial boards. He is a member of the Advisory Review Board of Journal of Materials Resenrch. He served as Chairman of the Solid State Sciences Committee, and was a member of the Committee on Advanced Energy Storage Systems and the Committee on Battery Materials Technology of the National Academy of Sciences-National Research Council, as well as numerous other technical and governmental committees.

\section{Herbert H. Johnson}

\section{Councillor}

Herb Johnson is professor of materials science and engineering at Cornell University, where he has been a faculty member since 1960 . His research interests include hydrogen in metals, phase stability, thermodynamics of solids, and corrosion. He has more than 50 publications in these areas.

Johnson is a member of The Metallurgical Society, American Society for Metals, American Physical Society, American Association for the Advancement of Science, American Society for Engineering Education, and Sigma $X_{i}$. He was director of the Materials Science Center at Cornell from 1974 to 1984 . He has served in numerous advisory and consulting capacities for national laboratories, university and other educational panels, and industrial firms. He has been designated as chair (1987-89) of the Solid State Sciences Committee of the National Research Council. He is a Fellow of American Society for Metals and has been designated ASM's 1986 Campbell Memorial Lecturer.

\section{John M. Poate}

\section{Councillor}

John Poate is head of the Interface Physics Research Department at AT\&T Bell Laboratories in Murray Hill, New Jersey. His research interests in recent years have centered on the properties of thin films and the near-surface properties of matter. This work is closely a ssociated with ion and laser beams for the modification and analysis of material properties. His publications include over 200 papers; co-authorship of three monographs on thin-film reactions, laser annealing of semiconductors, and ion implantation; and co-editorship of five conference proceedings. Poate is past president of MRS and a Fellow of the American Physical Society. He has been active since 1977 in MRS affairs, from co-organization of the first laser annealing symposium in 1979 to this year's symposium on Heteroepitaxy on Si. He has just finished serving on a National Academy of Sciences Committee evaluating the competitiveness of U.S. Materials Science in the field of advanced processing of electronic materials.

\section{W. (Woody) White}

Councillor

Woody White joined the Solid State Division of Oak Ridge National Laboratory in 1975 . He is group leader of the Ion-Solid Interactions Group and director of the Surface Modification and Characterization Facility. His research interests include ion implantation, laser annealing, ion beam analysis, ion beam modification of materials, and surface physics. He has over 150 publications and eight patents to his credit. In addition to his association with MRS, he is also a member of the American Physical Society.

White has been very active in the $\mathrm{Ma}$ terials Research Society in many capacities over the last eight years. He served as First Vice President in 1983 and President of MRS in 1984. During this time, when MRS was growing rapidly, he was one of the key individuals to lead this growth. He has chaired a number of the Society's committees, including Publications, Long-Range Planning, Nominating, and Awards. He was chair of the Select Committee which established the MRS headquarters and helped to guide its implementation. He was a meeting chair for the 1981 Boston Meeting and a co-chair of both the 1979 laser annealing symposium and the 1983 ion implantation symposium. Currently he is exploring alternatives for future MRS headquarters space requirements, is a Principal Editor for the Journal of Materials Resenrch, and serves as a member of several of the Society's committees.

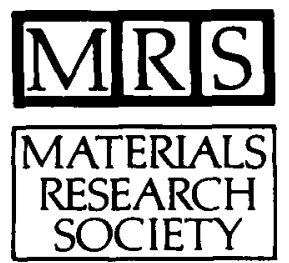

